\title{
TRAS EL OBJETO DESEADO. ALGUNAS IDEAS SOBRE LA FOTOGRAFÍA ${ }^{1}$
}

\author{
BEHIND OF THE DESIRED OBJECT. SOME IDEAS ABOUT PHOTOGRAPHY
}

\author{
Bibiana Peña \\ Diseñadora Gráfica \\ Universidad del Valle \\ bibianuz@gmail.com \\ Juan Camilo Buitrago \\ Profesor del Departamento de Diseño \\ Universidad del Valle \\ juan.buitrago@correounivalle.edu.co
}

Resumen: La fotografía es un tipo de imagen altamente icónica que debate su sentido entre ser un documento con el cual se congela el tiempo y se recrea la ilusión de realidad, y ser el sustrato del padecimiento y búsqueda de la plenitud, como proceso de materialización de la embriaguez y la construcción de mirada. En la enorme cantidad y calidad de grises que se producen en esta oposición, la fotografía está detrás del objeto deseado al que se refirió Barthes alguna vez: tanto en el sentido de su búsqueda, como en la idea de su posición: detrás de aquello.

Palabras Clave: Fotografía, Documento, Barthes, Patrimonio.

Abstract: The photography is a type of highly iconic image gets debate his sense between being a document which freezes time and the illusion of reality is recreated and be the substrate of suffering and quest for fulfillment, as a process of materialization of drunkenness and building a point of view. On the huge quantity and quality of gray that occur in this opposition, photography is behind the desired object to which Barthes spoke once: both in the sense of his quest, and the idea of their position: behind that.

Keywords: Photography, Document, Barthes, Patrimony. 


\section{La Imagen del Pasado}

"Las fotografías no son tanto un instrumento de la memoria como una invención o un sustituto de esta"

(Berger, 2000, p. 48)

Una foto es siempre una imagen del pasado, da cuenta de un tiempo transcurrido. Con ella recordamos, hacemos memoria de sucesos y épocas. Ver una fotografía evoca sentimientos o emociones que se vivieron en un momento determinado; es revivir el pasado una y otra vez cada que volvemos a ellas.

Siempre es una experiencia ver fotos de nuestros álbumes familiares: conocemos a muchas personas a través de ellas, incluso, mucho antes de poder verlas personalmente. ¿Qué decir de las fotos de las que no fuimos testigos?, ¿de las que no fuimos protagonistas porque ni siquiera habíamos nacido? Ellas nos permiten ver a través de los ojos de un anónimo que se vuelve médium, en un fascinante viaje hacia el pasado y, de una extraordinaria manera, observamos un momento ajeno, convirtiéndonos imaginariamente en protagonistas de él.

"Las fotografías nos permiten imaginar el pasado de una forma más clara, más viva” (Burke, 2005, p. 17). De alguna manera, por eso también permiten anticipar el futuro; a través de ellas podríamos imaginar cómo es una persona que aún no conocemos: en el momento en el que nos topamos con ella la reconocemos gracias a su representación fotográfica: podríamos adelantarnos, viajar al futuro e imaginar cómo sería conocer a ese ser; con una fotografía de algún lugar, podríamos imaginar cómo se sentiría ocupar ese espacio.

Ahora bien, es posible dividir la fotografía en dos categorías que responden a dos grandes funciones culturales según Roman Gubern (1987):

La primera categoría es la de foto mimética que guarda fidelidad óptica con lo fotografiado. En esta, entra por ejemplo la foto de reportaje, su función es la de la memoria y ella, la memoria, puede ser individual y se da en la experiencia privada. También puede darse en el spectrum, como dice Barthes (1994), sujeto fotografiado que ve la imagen de sí mismo: es la fotografía que vemos de nosotros mismos, en aquel memorable cumpleaños y que reposa en los ya viejos álbumes que mencionábamos hace un momento. Por otra parte, está la memoria colectiva, de uso público como dice Berger, que contribuye a la memoria del desconocido. Presenta un suceso, ofrece información ajena a toda experiencia vivida y se relaciona con un espectador anónimo como sucedería con las fotografías de un periódico. 
La segunda categoría es la de foto no mimética en la que no necesariamente se guarda fidelidad óptica. Su función principal es la creación y se centra en la expresión del autor: por ejemplo los famosos fotogramas de Man Ray.

Estas categorías no son excluyentes entre sí, pues toda fotografía, es, en cierta medida, memoria y creación o reproducción y expresión a la vez.

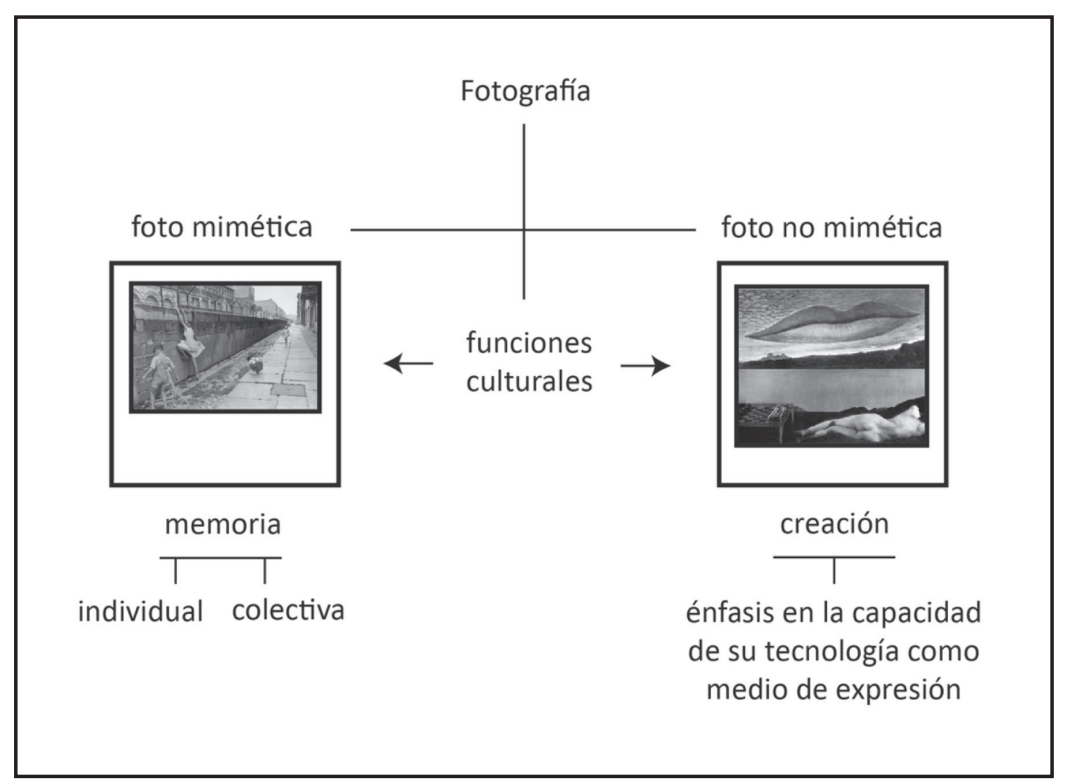

Esquema 1. Funciones de la fotografía según Gubern y Berger. Fotografías: Izquierda. Henri Cartier Bresson. Berlin wall. h.1962. Derecha. Man Ray. Observatory time-the lovers. h. 1934. Gráfico por Bibiana Peña.

En otro sentido, para Peter Burke (2005), tanto como los textos y los testimonios orales, las imágenes son una forma importante de documento y contribuyen al estudio y construcción del relato histórico. Reflejan un testimonio ocular, proporcionando información a otro nivel, ese nivel que trasciende las palabras, en el que ni siquiera el texto más descriptivo podría expresarse.

Los historiadores agudizando el ojo y mirando más allá de lo literal, de lo explícito, logran ver lo que hay tras el telón como decodificando un mensaje cifrado. Al estilo de personajes literarios como el inspector Dupín, Sherlock Holmes o el encantador monje franciscano William de Baskerville, los detalles más insignificantes de un escenario se convierten en cada uno de ellos, en plenos indicios que señalan con precisión la reconstrucción de los hechos. De manera similar los historiadores tamizan distintos tipos de imágenes como pinturas, estatuas, grabados o fotografías y apoyándose en otros documentos, logran extraer elementos que pueden dar cuenta de estructuras sociales, de la historia de la vida cotidiana, de la cultura material, de la historia del cuerpo etc. 
Las fotografías parecen ser los casos en que de forma más clara y directa puede observarse ese testimonio histórico que callan las imágenes, posiblemente por la ilusión de fidelidad con que logra representar la realidad, como dijimos hace un momento.

Y es precisamente, como si lo que está en la imagen fotográfica fuese la realidad, que Armando Silva en su Álbum de Familia (1998) relata cómo, cuando estaba haciendo su trabajo de campo, las personas que le mostraban fotos de sus familiares decían: este es mi tío fallecido o esta es mi hermana menor. Es como si al tener una fotografía de alguien o algo, poseyéramos al spectrum: poseyéramos a lo fotografiado. Es un viejo espíritu que no parece abandonar la condición humana. Ernst Gombrich (2007) expuso con claridad la relación que sostiene el hombre con la imagen desde casos como el egipcio. Para Gombrich, la contundencia y la claridad en la representación de los jeroglíficos durante ciertas dinastías egipcias, están relacionadas con la idea de concentrar las esencias de lo representado allí, en la imagen, con el propósito de que, una vez el faraón muerto cobre vida en el 'más allá', pueda hacer uso de todos los elementos necesarios para sortear su devenir. O la vieja anécdota del colmillo del león que uno de los osados guerreros de una tribu lograra arrancar de esa presa por primera vez, para colgárselo en el pecho y, con ayuda de sus pares, recrear la ilusión de tener condensado el poder, y ser aquel animal significante de fuerza y dominio. Como esa popular y significativa costumbre de guardar la foto del ser amado en la billetera, como si pudiera llevarlo consigo mismo a todas partes para que lo acompañe siempre y poderlo presentar en cualquier momento "la fotografía es la momificación del referente [...] el referente se encuentra ahí en un tiempo que no le es propio" (Freund, 1983, pp. 24 y 26), el tiempo presente.

Quizá por ese mismo sentido, la fotografía también parece otorgarnos cierto poder sobre el pasado, poder que se materializa en otra conocida costumbre: la de intervenir nuestras fotos, recortando a quien queremos excluir de ella, como realizando un ritual en el que es posible editar los recuerdos. Visto desde esta perspectiva la fotografía nos otorga la posibilidad de volver tangible el recuerdo y borrar de él lo que ya no es necesario conservar:

las fotografías no son tanto un instrumento de la memoria como una invención o un sustituto de ella [...] ¿qué hacía las veces de la fotografía antes de la invención de la cámara fotográfica? [...] la respuesta más reveladora sería: la memoria. Lo que hacen las fotografías allí afuera, en el espacio exterior a nosotros, se realizaba anteriormente en el marco del pensamiento. (Berger, 2000, p. 48)

En la película Memento (2000), Leonard -su protagonista- sufre un daño cerebral que le ocasiona un tipo de amnesia que a su vez le impide retener nuevos recuerdos. Como sustituto de su memoria, utiliza fotos instantáneas como parte de un sistema de registro de aquellos recuerdos que no puede almacenar empleando "la cámara como un instrumento que contribuye a la memoria viva" (Berger, 2000, p. 50), a su memoria viva. Este caso ejemplifica cómo la fotografía es el "recuerdo de una vida que está siendo vivida” (Berger, 2000, p. 50) y, en cierta medida, muestra cómo fotografía y memoria parecen unidas por un delgado hilo de sustitución histórica, así no suframos de amnesia como Leonard. 
De esta manera la fotografía es en un sólo instante documento histórico y tótem. Es lo primero, pues da cuenta de que un suceso realmente pasó. En esta dimensión, se convierte en un tipo de documento del que sentidos e indicios permiten la lectura de una vastísima cantidad y cualidad de asuntos sociales. Es lo segundo -tótem-, ya que en un sentido esotérico captura la esencia de las cosas invocando al referente, al espectrum, cada vez que vemos la imagen; ya que, como diría Barthes, no es la foto lo que vemos sino lo representado, posibilitando recrear ese viejo espíritu humano por medio del cual hemos querido apropiarnos de las características de aquello que es representado para congelarlo en el tiempo y condensarlo en la materia.

\section{La verosimilitud de un artificio}

"Aunque las fotos no mienten, los mentirosos pueden hacer fotos" Lewis Hine (Burke, 2005, p. 25)

Aunque reconocemos en una foto al objeto que logra evocar situaciones tan vívidas, quizá por su cercanía con la "realidad", también es conocido el debate que se ha generado desde hace mucho al trazar los límites entre la veracidad y la objetividad dentro de ella misma. Burke advierte sobre la trampa que resulta asumir la imagen y específicamente la fotográfica como la duplicación de un hecho real al construir el relato histórico: "La idea de objetividad, planteada ya por los primeros fotógrafos, venía respaldada por el argumento de que los propios objetos dejan huella de sí mismos en la plancha fotográfica cuando ésta es expuesta a la luz, de modo que la imagen resultante no es obra de la mano del hombre, sino del pincel de la naturaleza” (Burke, 2005, p.26). Y como generalmente nos dejamos seducir por la ilusión de que una foto cuenta la verdad y nada más que la verdad, vale la pena mencionar algunos argumentos que relativizan este planteamiento.

"Aunque las fotos no mienten, los mentirosos pueden hacer fotos" y más aún -hasta cierto punto- un mentiroso que dispone un escenario, disfraza la realidad o controla un pincel de Photoshop. Una de las partes determinantes en la fotografía, en palabras de Barthes, es el "operator", quien elige qué dejar dentro y qué dejar fuera del encuadre y quien controla casi siempre la escena. Hasta el más ingenuo de los fotógrafos manipula la imagen: al tomar la foto de una celebración familiar, el operador sugiere a los asistentes gritar: ¡whisky! El resultado... una gran sonrisa: en apariencia todos los asistentes al evento la pasaron de maravilla. Difícilmente sabremos cuáles de los asistentes realmente disfrutaban de la celebración. 
En otros casos los "mentirosos" pueden ser los modelos. Viene a nuestra mente una idea de Barthes que tiene que ver no tanto con mentir o posar sino más bien con la proyección de los deseos, anhelos y fantasías del ser: "ante el objetivo soy aquel que creo ser, aquel que quisiera que crean, aquel que el fotógrafo cree que soy, aquel de quien se sirve para exhibir su arte" (1994, p. 45). Burke menciona el caso del Duque Federico da Montefeltro en el siglo XV; él había perdido un ojo por lo que seguramente siempre era representado de perfil, quizá del lado que parecía digno de mostrar, posiblemente por elección propia o por decisión del autor del retrato.

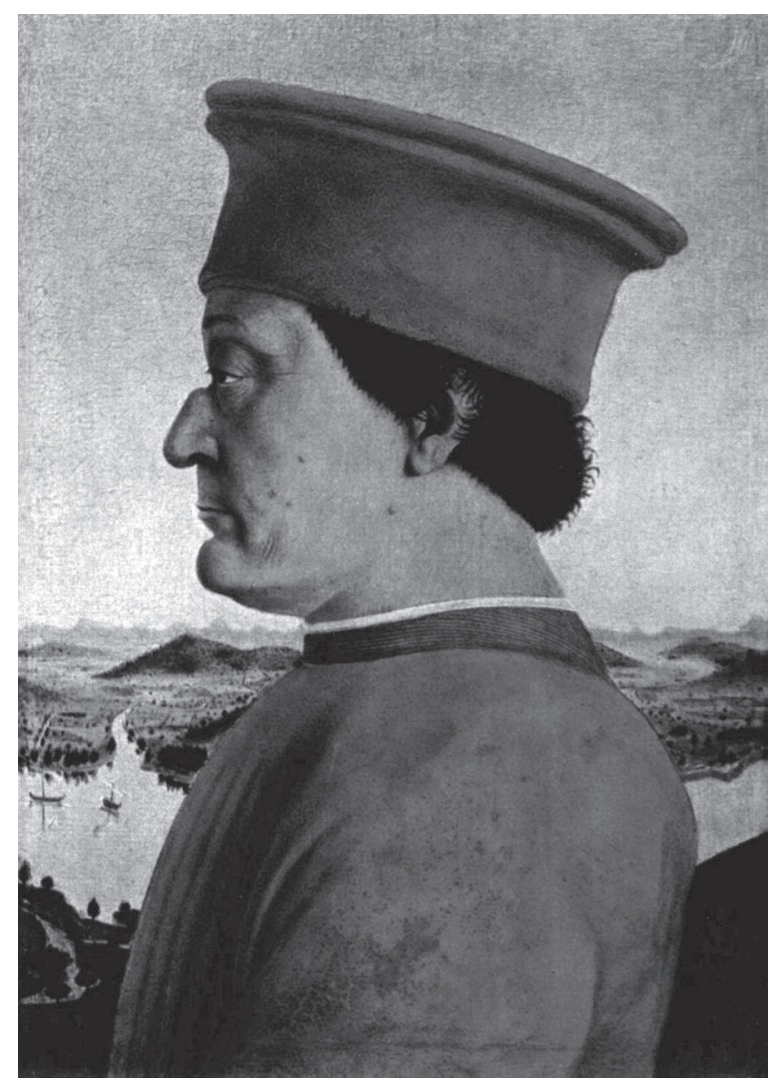

Imagen 1. Piero della Francesca. Federico II da Montefeltro. h.1465. Óleo sobre tabla, 47 x $33 \mathrm{~cm}$. Galería de los Uffizi.

El otro caso es el de Carlos V de quien se sabe tenía una pronunciada quijada gracias a los informes de embajadores extranjeros. En sus retratos, la mítica quijada del emperador era siempre disimulada por los pintores, incluso por Tiziano (Burke, 2005).

Quizá la imagen representada de Carlos V corresponda a la de quien él quería ser o a la que el autor quería ver: "Los modelos se ponen sus mejores galas para posar, de modo que los historiadores se equivocarían si trataran el retrato como un testimonio de la vestimenta cotidiana” (Burke, 2005, p. 31). 


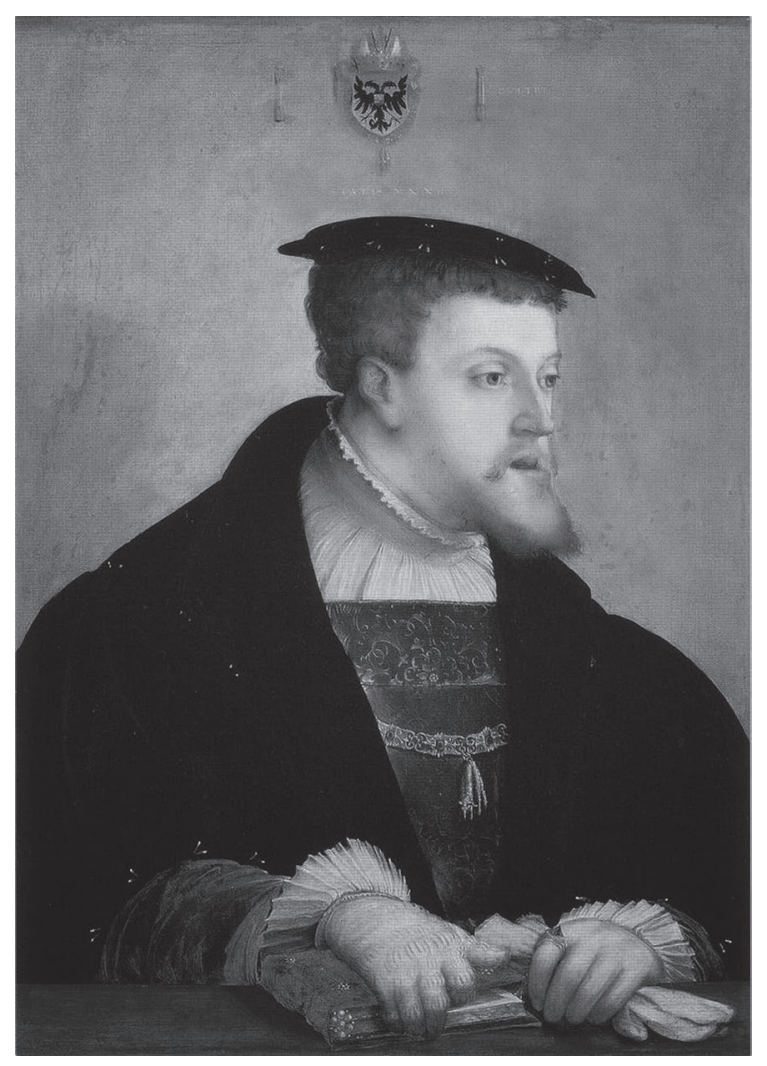

Imagen 2. Cristoph Amberger. Retrato de Carlos V emperador del Sacro Imperio. c 1532. Gemäldgalerie. Berlin.

Otras pruebas del artificio de la fotografía las proporciona Gubern en La Mirada Opulenta (1987). La principal prueba y de la cual se derivan las demás, es que la fotografía no es una simple duplicación fotoquímica o fotodigital -agregaríamos para épocas más recientesde nuestra percepción óptica, pues la cámara altera la representación en relación con la percepción binocular propia del ser humano.

Lo que vemos en una fotografía no es lo mismo que vemos con nuestros propios ojos, pues la imagen está contenida por un formato bidimensional. Al perderse la tercera dimensión, este espacio (el real) es remplazado por un espacio ilusorio. La ilusión óptica de profundidad y relieve se da mediante la perspectiva lineal heredada de la pintura renacentista. Y aunque el espectador desplace la cabeza, la imagen no cambia como sí ocurriría al mirar una escena real. No es lo mismo ver con nuestros dos ojos que mirar con uno a través de un pequeño agujero rectangular en el momento de tomar una foto -para hacer apología de los medios mecánicos- y aunque en el caso de la fotografía digital contemos con una pantalla LCD, la percepción de la imagen sigue estando limitada por el encuadre que incluye algunos elementos y excluye otros.

El ojo humano no encuadra, la delimitación de lo que observa es distinta. En una foto no hay movimiento, precisamente ésta congela el movimiento, atrapando un instante que hace parte de una gran secuencia de ellos: aparentemente aquel que para el fotógrafo tiene mayor interés y al que Bresson llamó “el instante decisivo” (Gubern, 1987, p. 156). 
La textura irregular formada por los granos de plata y por los pixeles, en el caso de la fotografía digital, distorsiona la realidad o el parecido con ella. La alteración del matiz, la luminosidad o saturación de los colores, los colores fotográficos distorsionan los valores cromáticos de los elementos fotografiados. Existe la posibilidad de alterar la escala de representación, como en el caso de la foto para una gran valla publicitaria o de una para documentos de identificación. Anulación de estímulos que provienen de los demás sentidos como el sonido, el tacto, la temperatura, el gusto y el olor que desempeñan un papel importante en la evocación de imágenes del pasado o en el reconocimiento de lugares y/o sujetos.

La fotografía no es una duplicación fiel de la percepción humana, sino una representación icónica altamente convencional. Por eso el término realismo aplicado a la fotografía no tiene tanta relación con lo perceptual sino una estrecha relación con la dimensión histórica. Es decir, lo que la foto muestra es la certificación química o digital de una existencia pasada que aconteció una vez ante el objetivo de la cámara. Como dijimos anteriormente, un testimonio ocular.

Según Barthes (1994), en la fotografía el poder de autentificación prima sobre el poder de representación. Podríamos presumir que por esta razón algunos documentos de identificación llevan consigo una foto y que de ahí también la aplicación de quienes han querido falsificar la historia utilizando como pruebas inapelables fotos trucadas que se presentan como auténticas, es decir, atribuyendo a un tipo de fotografía (la foto posada o puesta en escena) la condición de otro distinto (el reportaje o la foto documental), como sucedió en algunas de las famosas denuncias en el campo:

Algunos fotógrafos intervinieron más que otros con el fin de adecuar objetos y personas a sus intenciones. Por ejemplo en las imágenes de la pobreza de las zonas rurales de los Estados Unidos durante los años treinta que fotografió, Margaret Bourke-Withe (1904-1971), contratada por las revistas Fortune y Life, intervino más Dorothea Lange en las suyas. Igualmente algunos de los "cadáveres" que podemos contemplar en las fotos de la Guerra Civil americana eran, al parecer, soldados vivos que posaron amablemente para la cámara. La autenticidad de la foto más famosa de la Guerra Civil española, la Muerte de un soldado de Robert Capa, publicada por primera vez en una revista francesa en 1936, ha sido puesta en duda por razones similares. (Burke, 2005, p. 28) 


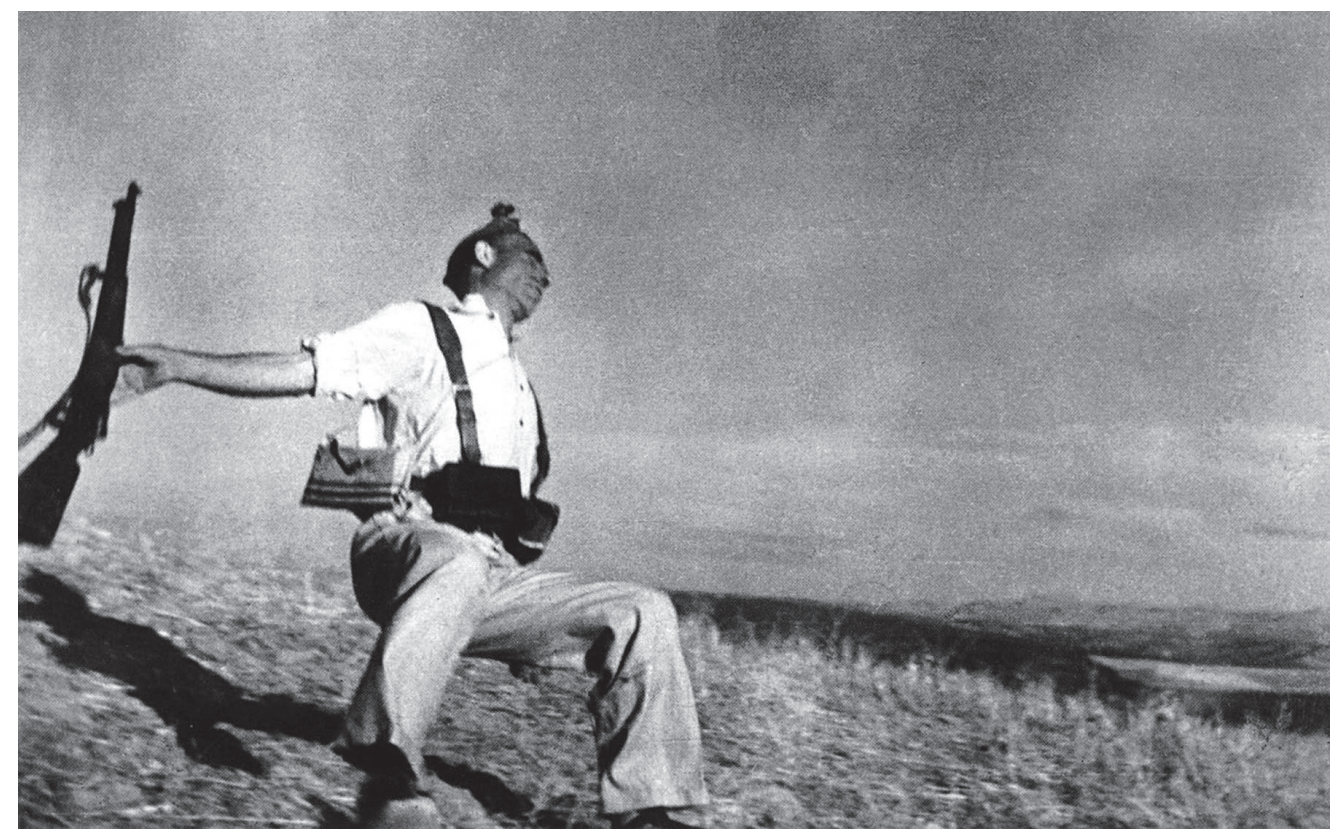

Imagen 3. Robert Capa. Muerte de un soldado. h., 1936.

Para hablar de casos más recientes, con la fotografía digital surge la duda desde un inicio ya que, gracias a los fotomontajes y retoques digitales, no acreditamos que la mujer que vemos en una imagen publicitaria, por ejemplo, sea similar a la que se nos muestra.

La subjetividad del autor condiciona la imagen, la intención, pues éste siempre decide qué dejar dentro y qué dejar fuera, desde el acto mismo del encuadre:

Los historiadores al igual que los fotógrafos, seleccionan qué aspectos del mundo real van a retratar. 'Todos los grandes fotógrafos se han sentido perfectamente libres de seleccionar los motivos, el marco, la lente, el filtro, la emulsión y el grano, según su sensibilidad' [dice Siegfried Kracauer]. El fotógrafo Roy Stryker expresaba esta misma idea fundamental en 1940. 'Desde el momento en que un fotógrafo selecciona un tema”, decía, "está trabajando sobre la base de una actitud sesgada análoga a la que podemos apreciar en los historiadores'. (Burke, 2005, p. 27)

En este sentido el fotógrafo sólo deja ver al espectador lo que él quiere mostrar.

Gubern (1987) enumera más razones por las cuales la subjetividad del autor condiciona la imagen eligiendo una película determinada, a blanco y negro o a color. Eligiendo el punto de vista y el encuadre, regulando el enfoque o desenfoque, regulando la apertura del diafragma, decidiendo el tiempo de exposición, el momento del disparo, interviniendo en los procesos químicos y físicos posteriores al disparo, y el enorme universo de la intervención digital en dos momentos distintos pre foto y post foto. 


\section{el hacer}

\section{"operator"- fotógrafo}

remitente

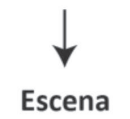

Matricial

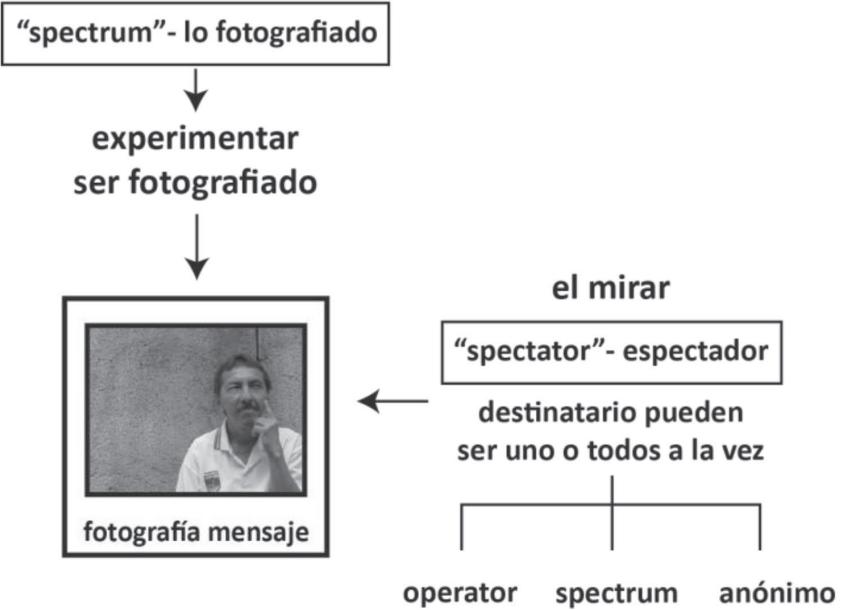

Esquema 2. El acto fotográfico de Barthes. Gráfico y fotografía por Bibiana Peña.

Podemos decir que aunque la fotografía lleva implícito ese poder de autenticación, no es más que una ilusión pues es el resultado de la operación de una máquina -la cámaray de la intervención de un operario -el autor- o de la dramaturgia del fotografiado. Por ser un artificio tan verosímil, nos seduce la ilusión de realismo. Lo representado en la foto no es del todo irreal, pues existe en el mundo de las imágenes, quizás en una realidad paralela con la que nos gusta fantasear.

\section{Sobre lo que no se puede decir con palabras}

"Heme pues a mí mismo como medida del "saber”fotográfico".

(Barthes, 1994)

Tratando de expresar aquello que se siente al mirar las fotografías de un tono rojizo contenidas en un viejo álbum y en las que nuestros padres podrían parecer en plenitud, felices, tan apacibles... inevitablemente debemos decir que nada puede ser dicho; más bien, que muy poco se puede decir. Ante la emoción de ver unos cuerpos que resultan cercanos, tan conocidos pero que a su vez son ya tan distantes, tan lejanos, tan invisibles porque ese gesto que se dibujaba en sus rostros, en sus cuerpos posiblemente haya desaparecido. 
Como tantas producciones materiales inventadas por el hombre, la imagen fotográfica es expresión de lo indecible, de lo indescriptible, de lo inefable de forma consciente o inconsciente, como lo describe Burke: "Las imágenes son testigos mudos y resulta difícil traducir a palabras el testimonio que nos ofrecen. Pueden haber tenido por objeto comunicar su propio mensaje, pero no es raro que los historiadores hagan caso omiso de él para "leer entre líneas" las imágenes e interpretar cosas que el artista no sabía que estaba diciendo" (2005, p. 18). Siendo un desprevenido fotógrafo que la utiliza como un medio de registro, diciendo cosas que no sabe que está diciendo o con toda intencionalidad, y haciendo uso de ella como medio de expresión consciente.

La fotografía es un objeto inclasificable, dice Barthes. Ver una foto no es a ella a quien vemos, pues es casi invisible y siempre vemos lo fotografiado: al ser amado, al paisaje recordado, al "objeto deseado [...] No es posible ver la fotografía a primera vista, esto requiere un esfuerzo mayor, un acto de reflexión" (1994, p. 35).

Lo que no se puede decir con palabras acerca de la emoción de ver una fotografía o, si generalizamos, de ver una imagen, seguramente tiene que ver con que lo que ésta dice tampoco puede verbalizarse: sólo es posible expresarlo mediante la imagen fotográfica misma y ahí simplemente se fosiliza.

La imagen fotográfica es una expresión de lo indecible, de lo indescriptible, de lo inverbalizable. La fotografía capta una porción del pasado y la trae al presente, a todos los presentes y futuros posibles. Interrumpe el movimiento, toma una porción de un todo, lo enmarca y dirige la mirada hacia ella. Como si señalara con el dedo, con ese dedo con el que no debíamos apuntar, según nos decían cuando éramos niños. El mismo dedo al obturar.

Como dijera Susan Sontag "Fotografiar es conferir importancia" (Gubern, 1987, p. 156).

“... mas quem já observou os instantâneos de Henri Cartier-Bresson ou de Robert Capa [...] sabe que por trás do disparo do obturador está memória, escolha, em uma palavra: construção. Aquilo que permite reagir fulminantemente ao acaso é o lento acúmulo da experiência...”

(Ginzburg, 2005, p. 169) 


\section{Notas}

' El presente artículo es producto del proyecto de grado de Bibiana Peña titulado "Acerca de Henry. Una mirada a la Afasia". Este proyecto es dirigido por Juan Camilo Buitrago y está inscrito en la línea de Narrativas Visuales del grupo de investigación Nobus.

\section{Referencias}

Barthes, R. (1994). La cámara lúcida: notas sobre la fotografía. España: Paidos.

Berger, J. (2000). Usos de la fotografía. Elementos, ciencia y cultura, 47-51.

Burke, P. (2005). Visto y no visto. El uso de la imagen como documento histórico. Barcelona: Crítica.

Freund, G. (1983). La fotografía como documentos social. España: Gustavo Gili.

Ginzburg, C. (2005). Conversar com Orion. Revista Esboços , 12 (14), 163-170.

Gombrich, E. (2007). La Historia del Arte. China: Phaidon Press Limited.

Gubern, R. (1987). La mirada opulenta. Exploración de la iconósfera contemporánea. Barcelona: Gustavo Gili.

Nolan, C. (Dirección). (2000). Memento [Película].

Silva, A. (1998). Álbum de familia: la imagen de nosotros mismos. Bogotá: Norma.

Revisado: noviembre 10 / Aprobado: noviembre 30 de 2014 